\title{
HIV testing service awareness and service uptake among female heads of household in rural Mozambique: results from a province-wide survey
}

Heather N Paulin ${ }^{1 *}$, Meridith Blevins, ${ }^{2,5}$, John R Koethe ${ }^{1}$, Nicole Hinton ${ }^{2}$, Lara ME Vaz ${ }^{4,6,7}$, Alfredo E Vergara ${ }^{4,5}$, Abraham Mukolo ${ }^{4,5}$, Elisée Ndatimana ${ }^{6}$, Troy D Moon ${ }^{3,5,6}$, Sten H Vermund ${ }^{3,5}$ and C William Wester ${ }^{1,5}$

\begin{abstract}
Background: HIV voluntary counseling and testing (VCT) utilization remains low in many sub-Saharan African countries, particularly in remote rural settings. We sought to identify factors associated with service awareness and service uptake of VCT among female heads of household in rural Zambézia Province of north-central Mozambique which is characterized by high HIV prevalence (12.6\%), poverty, and suboptimal health service access and utilization.

Methods: Our population-based survey of female heads of household was administered to a representative two-stage cluster sample using a sampling frame created for use on all national surveys and based on census results. The data served as a baseline measure for the Ogumaniha project initiated in 2009. Survey domains included poverty, health, education, income, HIV stigma, health service access, and empowerment. Descriptive statistics and logistic regression were used to describe service awareness and service uptake of VCT.
\end{abstract}

Results: Of 3708 women surveyed, 2546 (69\%) were unaware of available VCT services. Among 1162 women who were aware of VCT, 673 (58\%) reported no prior testing. In the VCT aware group, VCT awareness was associated with higher education $(\mathrm{aOR}=2.88 ; 95 \% \mathrm{Cl}=1.61,5.16)$, higher income $(\mathrm{aOR}=1.41,95 \% \mathrm{Cl}=1.06,1.86)$, higher numeracy $(\mathrm{aOR}=1.05$, $\mathrm{Cl} 1.03,1.08)$, more children < age 5 in the home $(\mathrm{aOR}=1.53 ; 95 \% \mathrm{Cl}=1.07,2.18)$, closer proximity to a health facility $(\mathrm{aOR}=1.05 ; 95 \% \mathrm{Cl}=1.03,1.07)$, and mobile phone ownership $(\mathrm{aOR}=1.37 ; 95 \% \mathrm{Cl}=1.03,1.84)$ (all $p$-values $<0.04)$. Having a higher HIV-associated stigma score was the factor most strongly associated with being less likely to test. $(\mathrm{aOR}=0.41 ; 95 \% \mathrm{Cl}=0.23,0.71 ; \mathrm{p}<0.001)$.

Conclusions: Most women were unaware of available VCT services. Even women who were aware of services were unlikely to have been tested. Expanded VCT and social marketing of VCT are needed in rural Mozambique with special attention to issues of community-level stigma reduction.

Keywords: HIV/AIDS, Voluntary Counseling and Testing (VCT), Resource limited settings, Southern Africa, Mozambique, Rural, HIV awareness

\section{Background}

Despite global efforts to scale up human immunodeficiency virus (HIV) prevention measures and voluntary counseling and testing (VCT) for HIV, testing coverage remains low in many sub-Saharan African countries, particularly in rural areas [1-4]. Similar to many Sub-Saharan African countries,

\footnotetext{
* Correspondence: hnpaulin@gmail.com

'Department of Medicine, Division of Infectious Diseases, Vanderbilt University School of Medicine, 1611 21st Avenue South, A-2200, Medical Center North, Nashville, TN, USA

Full list of author information is available at the end of the article
}

Mozambique has increased the number of total adults undergoing HIV testing (ages 15-49) between 2003-2009, although baseline testing rates (e.g., 2003 and years prior) were very low.

Thus, by 2009 only a minority of men (17.2\%) and women (33.6\%) reported they had ever received HIV testing and were aware of their status [5]. Programmatic analyses of VCT and treatment initiatives supported by the United States government-funded President's Emergency Plan for AIDS Relief (PEPFAR) have focused primarily on urban and peri-urban populations. Fewer such evaluations 
have been conducted among persons receiving HIV care and treatment in rural, more remote settings [6-14].

Mozambique is one of the most HIV-affected countries in sub-Saharan Africa, with an estimated national HIV prevalence of $11.5 \%$ (ages 15-49) and 1.2 million persons (age 15+) living with HIV in 2009 [15,16]. In 2004, the Mozambican Ministry of Health (MISAU) launched a national antiretroviral treatment (ART) program, termed "tratamento antiretroviral" (TARV). By 2009, ART services were offered in all 10 provinces and 1 capital city, but care was still predominantly clustered in urban areas [17-20]. The importance of increased VCT participation has intensified with the growing body of evidence that early ART initiation may be a highly effective method to reduce new infections (i.e., treatment as prevention) [21-24]. As of 2010, it was estimated that approximately $32 \%$ of adults in Mozambique with advanced HIV disease are receiving ART, but coverage remains highest in urban areas $[16,18,25]$.

Zambézia is a predominantly rural province situated in north-central Mozambique, with a population near 3.8 million persons, making it the nation's 2 nd most populous province. Zambézia, has the 3rd highest HIV prevalence (among provinces) at 12.6\% (ages 15-64) in 2009 [15], faces numerous challenges including exceedingly high poverty rates, suboptimal health service access and utilization rates, and poor ART coverage, with an estimated 10\% ART coverage rate [15,18,26,27]. Other neighboring countries had low ART coverage rates, but Zambézia was certainly among the worst. The economy of Zambézia is primarily agrarian and piscatory, with only one large population center in Quelimane, the provincial capital (2007 census population of 193,343 persons) [28]. The national language is Portuguese and the five predominant local languages are Cisena, Elomwe, Echuabo, Cinyanja, and Emakhuwa [29]. The province has the highest unmet needs in terms of HIV/AIDS care treatment with recent statistics documenting that 20\% of Mozambique's persons living with HIV/AIDS live in Zambézia, with many of them residing in rural areas [15]. The province has a limited health infrastructure with 214 health facilities, including one provincial hospital and 6 rural hospitals. As of December 2012, it was estimated that only 33 of these health facilities were providing ART. We have calculated that if every HIV positive Zambézian ( $\approx 230,000$ persons) were to be identified and enrolled in care, each health facility would need to provide care for an average of 7,000 persons $[15,27]$.

The disproportionately higher burden of HIV disease among women in Mozambique is similar to the rest of southern Africa [19,30]. Furthermore, a 2010 report suggested that despite programs to increase VCT and treatment coverage, there has been no significant national reduction in the prevalence of HIV among females aged 15-24, in contrast to neighboring countries [20].
In Mozambique, Portuguese is the national language and VCT sites were first known as the Gabinete de Aconselhamento e Testagem Voluntária (GATV or Centres for Voluntary Counselling and Testing); they are now known as Unidades de Aconselhamento e Testagem em Saúde (UATS or Health Counselling and Testing Units). The motivation for changing the name in 2006-2007 was that GATV sites only tested for HIV. In an attempt to diminish stigma associated with attending a site known as the "HIV testing site" the UATS began providing counseling and testing for a variety of health issues including malaria, tuberculosis, family planning, as well as HIV. Access to VCT (UATS), provider-initiated counseling and testing (PICT), and ART services need expansion in rural Mozambique [31].

In this study, we describe factors associated with the women's VCT service awareness and utilization across the province through a representative survey.

\section{Methods}

The 5-year Strengthening Communities through Integrated Programming (SCIP) project, known locally as Ogumaniha, was initiated as a multi-faceted health and economic development initiative financed by the United States Agency for International Development (USAID) in Zambézia Province, Mozambique. As the monitoring and evaluation partner in the Ogumaniha project, Vanderbilt University and its local non-governmental organization, Friends in Global Health, conducted a baseline household survey in 2010 of more than 3,700 female heads of household throughout the province, including many remote communities.

\section{Sample design and data collection}

Our two-cluster sampling design was executed by the Chief Sampling Statistician from the Mozambican National Statistics Institute (Instituto Nacional de Estatística). Also, our two-stage cluster sampling design referenced a 2007 census based sampling frame that was utilized for all national surveys. A provincially representative sample of 264 enumeration areas was selected, with probability proportional to size according to the census (Figure 1). Enumeration areas were stratified into urban and rural areas; 206 of the enumeration areas (EAs) were selected from three "focus districts" (Alto Molócuè, Morrumbala, and Namacurra), further stratified by planned intervention.

The baseline survey data were collected during August-September 2010. Local authorities were notified prior to the arrival of the survey team. From topographic maps, the survey teams divided the EAs into four quadrants. Starting in the center of the assigned quadrant, interviewers selected a direction, then chose the first household in this direction (i.e. starting point), and then approached the nearest four households for interview. This household 


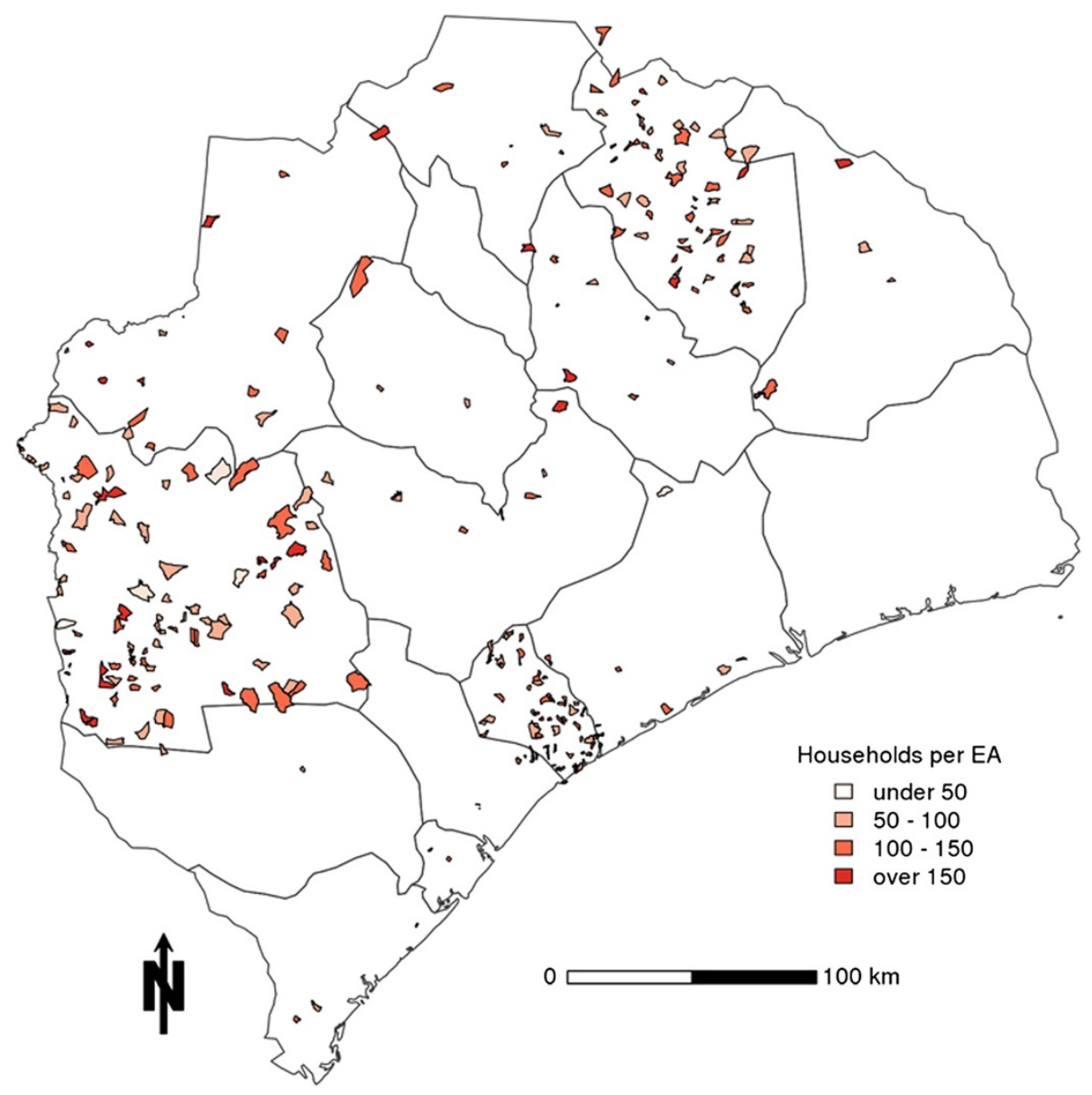

Figure 1 Enumeration Areas surveyed for the Ogumaniha baseline survey, Zambézia, Mozambique 2010.

selection approach was used following the failed attempt to use satellite imagery to list and randomly select households. Female interviewers conducted the survey with female heads-of-household, defined as the only or principal wife of the immediate family of the household.

The female head of household was chosen to be the respondent, as she is the most likely subject to be the most familiar with the health and care taking of the entire family. In polygamous families, the eldest wife was selected, which may have introduced bias if the remaining wives and their children were different.

Interviewers were trained to conduct interviews in Portuguese or in one of the five predominant local languages. Fourteen mobile teams, consisting of a team leader and four interviewers, administered the survey faceto-face using cell phones with an electronic questionnaire installed for data collection.

In cases where cell phone access was unavailable, the survey was administered face-to-face using a paper questionnaire and responses were later entered into the cell phone. Whenever possible, survey data were transmitted securely via a wireless network to a central server; when not possible, data were transferred by a backup system from cell phones to a location in Maputo, the nation's capital, and then uploaded to the central server.

\section{Survey instrument}

The Ogumaniha project was designed with a monitoring system to report on project performance indicators and included a baseline survey instrument. The survey was developed by a multi-disciplinary team of health, education, economics, and social science experts at University Eduardo Mondlane (UEM) in Maputo and Vanderbilt University in the USA. Based on the expert opinion of the team, questions and scales were chosen from previously validated national surveys in Mozambique and derived from human development theory [32]. Domains of inquiry for the 550 item survey instrument included demographics and child health information [33], literacy and numeracy [34], education achievement [35,36], agricultural practice, food security, dietary diversity and food coping strategies [37-39], material possession and consumption of goods presumed critical for well-being [40-44], income generation [45], social barriers and social participation, social 
support networks, decision making within the family and gender differences [46-49], self-agency and determination [50], reproductive health, malaria and HIV knowledge, attitudes and practices, HIV/AIDS stigma [51], and a numeracy score (range 0-57; with scores less than 16 indicating the ability to read individual letters only).

Three scales were employed in the analysis, all with a range of 0-100. Higher scores on the Quality of Life (QoL) scale reflect positive answers about short-term subjective well-being [52-54]. Higher scores on the Social Exclusion Stigma scale indicate a lack of willingness to support and/or interact with persons living with HIV/ AIDS (PLWHA) [55]. Higher scores on the Negative Labeling and Devaluation Stigma Scale indicate a negative judgment and/or stereotype PLWHA, including anticipating devaluation by peers if one were to become infected with HIV oneself [55]. Hence, a high QoL scale score suggests high QoL while high scores of the two stigma scales are both suggesting more stigma.

\section{Ethical review board oversight}

The study protocol was reviewed and approved by the National Committee of Bioethics for Health in Mozambique and the Institutional Review Board of Vanderbilt University. No incentive was provided to participants, and written informed consent was obtained for all study participants. A mark was permitted if a woman could not sign her name.

\section{Statistical considerations}

Estimates of descriptive statistics were weighted by the inverse of the household sampling probability. Continuous variables are reported as weighted estimates of the median (interquartile range). Categorical variables are reported as weighted percentages. Two multivariable logistic regression models were used to determine the relationship between specific variables (selected a priori) and awareness of HIV VCT service availability (model 1: unaware vs. aware of VCT and model 2: aware but never tested vs. aware and ever tested in a VCT setting).

Only respondents who answered if they had ever heard of VCT were included in the analysis. From 550 variables, and we pre-specified the following 18 variables of interest: age, years of formal education, distance to the nearest health facility, urban or rural residence, primary language of household, understanding of Portuguese, marital status, religion, household autonomy, number of children less than 5 years of age, income, household electricity, mobile phone ownership, literacy, numeracy, willingness to stigmatize and exclude people living with HIV/AIDS (PLWHA) using each stigma scale, and QoL.

To relax linearity assumptions, some continuous variables were included in the models using restricted cubic splines. Multiple imputation was utilized to account for missing values of predictors and to prevent case-wise deletion of missing data. We used the functions 'aregImpute' and 'fit.mult.impute' from the Hmisc package in R-software 2.15.1 (www.r-project.org) that used predictive mean matching to take random draws from imputation models; ten imputation data sets were used in the analysis. We fit generalized linear models with robust covariance matrix estimates to correct for correlated responses among households from the same enumeration area [56].

\section{Results}

We interviewed 3,749 female heads of household utilizing 14 survey teams over 49 days $(\approx 77$ interviews per day, median interview time 73 minutes) with a participation rate of $99.7 \%$. Among these, 3,708 (98.9\%) responded to questions on VCT knowledge and were included for analysis. Table 1 summarizes demographic information for the women who were head of household respondents. The median age of the group was 29 years (range: 16 to 90). Women had a median 2 years of formal education (range: 0 to 15). Most households (80\%) were located in rural areas; the median distance of each enumeration area to the health facility was 6.6 kilometers. Only 39\% of women reported understanding Portuguese with 8\% reported it as their primary language. The predominant religion was Catholicism (45\%). Most women (74\%) were married or in a common-law relationship. When asked who was the household decision maker regarding pregnancy health care and child health care, $67 \%$ stated that this was women together with men.

Fewer women were aware of VCT (31\% unweighted; $\mathrm{n}=1162)$ than were unaware $(69 \%$ unweighted; $\mathrm{n}=2546$; Table 1). Women unaware of VCT had lower median formal education compared to those aware of VCT $(0 \mathrm{vs}$. 3 years), lived further from the health facility (7.6 vs. 5.0 kilometers), and more frequently resided in rural areas (90\% vs. 66\%). In addition, women unaware of VCT less frequently understood Portuguese (33\% vs. $48 \%$ ) and less frequently reported Portuguese as the primary language spoken in their households ( $2 \%$ vs. $17 \%)$.

\section{Aware of VCT vs. unaware of VCT}

In the first model we identified numerous factors that were associated with being aware of VCT services in the province (Table 2). Older age was associated with lower probability of VCT awareness. Compared with women who were 50 years of age, 30 year old women had the highest likelihood of being aware (Adjusted Odds Ratio $[\mathrm{aOR}]=1.47$; 95\% confidence intervals $[\mathrm{CI}]=1.12,1.93$ ) . Compared with no formal education, women having received $>10$ years of formal education had a nearly 3 -fold higher odds of being aware that VCT services were available $(\mathrm{aOR}=2.88 ; 95 \% \mathrm{CI}=1.61,5.16)$. Residing in an urban compared to a rural setting also increased one's 
Table 1 Respondent and household characteristics by knowledge of volunteering counseling and testing from Ogumaniha baseline survey, Zambézia, Mozambique 2010

\begin{tabular}{|c|c|c|c|}
\hline & $\begin{array}{l}\text { Unaware of VCT } \\
(n=2546)\end{array}$ & $\begin{array}{l}\text { Aware of VCT } \\
(n=1162)\end{array}$ & $\begin{array}{l}\text { Combined } \\
(n=3708)\end{array}$ \\
\hline Age of respondent in years (range) ${ }^{a}$ & $30(23-38)$ & $27(23-35)$ & $29(23-37)$ \\
\hline Education in years (range) $^{a}$ & $0(0-3)$ & $3(0-5)$ & $2(0-4)$ \\
\hline Distance of Enumeration Area from health facility in km (range) ${ }^{a}$ & $7.6(4.4-11.3)$ & $5.0(1.0-9.3)$ & $6.6(3.3-10.3)$ \\
\hline \multicolumn{4}{|l|}{ Urban/rural ${ }^{\mathbf{b}}$} \\
\hline Rural & $90 \%$ & $66 \%$ & $80 \%$ \\
\hline Urban & $10 \%$ & $34 \%$ & $20 \%$ \\
\hline \multicolumn{4}{|l|}{ Primary language of household ${ }^{\mathbf{b}}$} \\
\hline Cinyanja & $12 \%$ & $20 \%$ & $15 \%$ \\
\hline Cisena & $18 \%$ & $6 \%$ & $13 \%$ \\
\hline Echuabo & $24 \%$ & $23 \%$ & $24 \%$ \\
\hline Elomwe & $44 \%$ & $34 \%$ & $40 \%$ \\
\hline Emakhuwa & $<1 \%$ & $<1 \%$ & $1 \%$ \\
\hline Portuguese & $2 \%$ & $17 \%$ & $8 \%$ \\
\hline Respondent understands Portuguese ${ }^{b}$ & $33 \%$ & $48 \%$ & $39 \%$ \\
\hline \multicolumn{4}{|l|}{ Marital status ${ }^{\mathbf{b}}$} \\
\hline Married/Common Law & $75 \%$ & $73 \%$ & $74 \%$ \\
\hline Divorced/Separated & $4 \%$ & $4 \%$ & $4 \%$ \\
\hline Single & $17 \%$ & $17 \%$ & $17 \%$ \\
\hline Widowed & $4 \%$ & $6 \%$ & $5 \%$ \\
\hline \multicolumn{4}{|l|}{ Religion $^{\mathbf{b}}$} \\
\hline Catholic & $44 \%$ & $45 \%$ & $45 \%$ \\
\hline Protestant & $14 \%$ & $16 \%$ & $15 \%$ \\
\hline Evangelical and Pentecostal & $17 \%$ & $16 \%$ & $16 \%$ \\
\hline Other Christian $^{c}$ & $3 \%$ & $7 \%$ & $4 \%$ \\
\hline Muslim & $10 \%$ & $7 \%$ & $9 \%$ \\
\hline Non-Christian Eastern & $3 \%$ & $2 \%$ & $2 \%$ \\
\hline Other ${ }^{c}$ & $9 \%$ & $7 \%$ & $8 \%$ \\
\hline \multicolumn{4}{|l|}{ Decision maker for pregnancy health care ${ }^{b}$} \\
\hline Both & $52 \%$ & $57 \%$ & $54 \%$ \\
\hline Men & $18 \%$ & $13 \%$ & $16 \%$ \\
\hline Women & $30 \%$ & $31 \%$ & $30 \%$ \\
\hline \multicolumn{4}{|l|}{ Decision maker for child health care ${ }^{b}$} \\
\hline Both & $66 \%$ & $70 \%$ & $67 \%$ \\
\hline Men & $16 \%$ & $11 \%$ & $14 \%$ \\
\hline Women & $18 \%$ & $20 \%$ & $19 \%$ \\
\hline
\end{tabular}

Legend:

${ }^{a}$ Continuous variables are reported as weighted estimates of median (interquartile range), with each observation being weighted by the inverse of the household sampling probability.

${ }^{b}$ Categorical variables are reported as weighted percentages, with each observation being weighted by the inverse of the household sampling probability.

c'Other Christian' includes Latter day Saint/Mormon and Jehovah's Witness. 'Other' includes Spiritual, Traditional Religions, and Agnostic or Atheist.

likelihood of being aware of VCT $(\mathrm{aOR}=2.31 ; 95 \%$ $\mathrm{CI}=1.45$, 3.68). For every 1 kilometer women resided closer to a health facility, the odds of VCT awareness increased by $5 \% \quad(\mathrm{aOR}=1.05 ; 95 \% \mathrm{CI}=1.03,1.07)$.
Understanding Portuguese was not a strong predictor of VCT awareness $(\mathrm{p}=0.4)$. However, female heads of household residing in homes where Portuguese was the primary spoken language had 2.5 times higher odds of 
Table 2 Multivariable logistic regression models: aware of VCT and ever tested in VCT

\begin{tabular}{|c|c|c|c|c|}
\hline & $\begin{array}{l}\text { Adjusted odds ratio for } \\
\text { aware of VCT } \\
(95 \% \mathrm{Cl})\end{array}$ & P-value & $\begin{array}{l}\text { Adjusted odds ratio for } \\
\text { ever tested in VCT } \\
(95 \% \mathrm{Cl})\end{array}$ & P-value \\
\hline Number of households in model & 3708 & & 1162 & \\
\hline Age (years) & & $0.02^{\mathrm{a}}$ & & 0.53 \\
\hline 20 & $1.10(0.82,1.47)$ & & $1.15(0.75,1.77)$ & \\
\hline 30 & $1.47(1.12,1.93)$ & & $1.10(0.82,1.47)$ & \\
\hline 40 & $1.18(1.01,1.38)$ & & $1.05(0.91,1.21)$ & \\
\hline 50 (ref) & 1 & & 1 & \\
\hline 65 & $0.85(0.55,1.31)$ & & $0.93(0.75,1.16)$ & \\
\hline Education (years) & & $<0.01^{\mathrm{a}}$ & & 0.21 \\
\hline 0 (ref) & 1 & & 1 & \\
\hline 1 & $0.99(0.89,1.09)$ & & $1.04(0.98,1.12)$ & \\
\hline 2 & $1.00(0.83,1.20)$ & & $1.09(0.95,1.25)$ & \\
\hline 5 & $1.32(0.98,1.79)$ & & $1.24(0.88,1.75)$ & \\
\hline 10 & $2.88(1.61,5.16)$ & & $1.54(0.78,3.05)$ & \\
\hline Distance to Clinic (per 1 kilometer decrease) & $1.05(1.03,1.07)$ & $<0.01$ & $1.00(0.97,1.03)$ & 0.96 \\
\hline Urban & $2.31(1.45,3.68)$ & $<0.01$ & $1.36(0.91,2.04)$ & 0.13 \\
\hline Primary Language & & $<0.01$ & & 0.32 \\
\hline Elomwe (ref) & 1 & & 1 & \\
\hline Cinyanja & $2.13(1.39,3.28)$ & & $1.11(0.56,2.20)$ & \\
\hline Cisena & $0.83(0.62,1.13)$ & & $0.92(0.59,1.45)$ & \\
\hline Echuabo & $1.83(1.38,2.43)$ & & $0.75(0.53,1.06)$ & \\
\hline Emakhuwa & $1.02(0.31,3.35)$ & & $0.36(0.04,3.20)$ & \\
\hline Portuguese & $2.53(1.37,4.70)$ & & $0.60(0.33,1.09)$ & \\
\hline Understands Portuguese & $1.10(0.89,1.35)$ & 0.38 & $1.29(0.95,1.75)$ & 0.12 \\
\hline Marital status & & 0.63 & & 0.21 \\
\hline Married/Common Law (ref) & 1 & & 1 & \\
\hline Single & $0.89(0.70,1.12)$ & & $1.35(.98,1.86)$ & \\
\hline Divorced/Separated & $0.79(0.52,1.12)$ & & $0.80(0.41,1.55)$ & \\
\hline Widowed & $0.95(0.65,1.38)$ & & $1.21(0.68,2.17)$ & \\
\hline Religion & & 0.99 & & 0.64 \\
\hline Catholic & 1 & & 1 & \\
\hline Protestant & $1.04(0.77,1.40)$ & & $1.26(0.80,1.98)$ & \\
\hline Evangelical and Pentecostal & $1.05(0.79,1.40)$ & & $1.23(0.78,1.96)$ & \\
\hline Other Christian ${ }^{c}$ & $1.03(0.66,1.61)$ & & $0.86(0.45,1.65)$ & \\
\hline Muslim & $1.01(0.73,1.40)$ & & $0.86(0.54,1.38)$ & \\
\hline Non-Christian Eastern & $1.13(0.62,2.06)$ & & $1.41(0.60,3.32)$ & \\
\hline Other ${ }^{c}$ & $1.16(0.84,1.60)$ & & $1.02(0.59,1.76)$ & \\
\hline Decisions made for seeking health care for a pregnancy & & 0.88 & & 0.77 \\
\hline Both (ref) & 1 & & 1 & \\
\hline Men & $1.01(0.74,1.37)$ & & $1.24(0.68,2.27)$ & \\
\hline Women & $1.06(0.84,1.34)$ & & $1.08(0.75,1.56)$ & \\
\hline
\end{tabular}


Table 2 Multivariable logistic regression models: aware of VCT and ever tested in VCT (Continued)

\begin{tabular}{|c|c|c|c|c|}
\hline Decisions made for seeking health care for a child & & 0.21 & & 0.31 \\
\hline Both (ref) & 1 & & 1 & \\
\hline Men & $0.75(0.54,1.05)$ & & $1.00(0.56,1.77)$ & \\
\hline Women & $1.04(0.81,1.33)$ & & $0.76(0.53,1.09)$ & \\
\hline Children Under 5 years of age & & 0.02 & & $0.02^{\mathrm{b}}$ \\
\hline None (ref) & 1 & & 1 & \\
\hline 2 & $1.24(1.03,1.48)$ & & $1.63(1.12,2.36)$ & \\
\hline 4 & $1.53(1.07,2.18)$ & & $1.29(0.95,1.75)$ & \\
\hline Monthly Income & & 0.04 & & 0.33 \\
\hline No Income (ref) & 1 & & 1 & \\
\hline 1-1000 Meticais & $1.19(0.99,1.43)$ & & $1.17(0.80,1.70)$ & \\
\hline$>1000$ Meticais (> $\approx \$ 1.00$ USD/day) & $1.41(1.06,1.86)$ & & $1.37(0.90,2.08)$ & \\
\hline Electricity & $0.95(0.59,1.55)$ & 0.85 & $0.98(0.57,1.67)$ & 0.94 \\
\hline Mobile Phone & $1.37(1.03,1.84)$ & 0.03 & $1.21(0.77,1.89)$ & 0.4 \\
\hline Literacy (per 1 point) & $1.00(0.99,1.00)$ & 0.36 & $1.00(0.99,1.01)$ & 0.61 \\
\hline Numeracy (per 1 point) & $1.05(1.03,1.08)$ & $<0.01$ & $1.02(0.98,1.06)$ & 0.34 \\
\hline Negative Labeling and Devaluation Stigma Scale (0-100) & & 0.73 & & $0.02^{\mathrm{b}}$ \\
\hline 0 & $0.98(0.88,1.10)$ & & $0.91(0.58,1.42)$ & \\
\hline 20 pts (ref) & 1 & & 1 & \\
\hline 40 & $1.02(0.91,1.15)$ & & $1.06(0.80,1.39)$ & \\
\hline 60 & $1.04(0.82,1.32)$ & & $0.76(0.51,1.13)$ & \\
\hline 80 & $1.07(0.75,1.52)$ & & $0.41(0.23,0.71)$ & \\
\hline Social Exclusion Stigma Scale (0-100) & & $<0.01^{\mathrm{a}}$ & & 0.89 \\
\hline 0 & $0.54(0.45,0.65)$ & & $0.99(0.88,1.11)$ & \\
\hline 20 pts (ref) & 1 & & 1 & \\
\hline 40 & $1.21(1.08,1.34)$ & & $1.01(0.90,1.13)$ & \\
\hline 60 & $0.82(0.65,1.04)$ & & $1.02(0.81,1.28)$ & \\
\hline 80 & $0.61(0.47,0.79)$ & & $1.02(0.73,1.45)$ & \\
\hline Wellbeing (Chronic quality of life score) (per 10 points) & $1.06(1.00,1.13)$ & 0.05 & $0.94(0.87,1.02)$ & 0.16 \\
\hline
\end{tabular}

VCT awareness $(\mathrm{aOR}=2.53 ; 95 \% \mathrm{CI} 1.37,4.70)$ compared to Elomwe (the most frequently spoken language among surveyed participants), and approximately twice the odds of VCT awareness compared to homes where Cinyanja and Echuabo were the predominant spoken dialects (adjusted odds ratios of 2.13 [95\% CI $=1.39,3.28]$ and 1.83 [95\% CI $=1.38,2.43]$, respectively).

Compared to women with no children, women with 2 children under 5 years of age were more likely to be aware of VCT $(\mathrm{aOR}=1.24 ; 95 \% \mathrm{CI}=1.03,1.48)$. Having even more children was associated with an even heightened awareness of VCT (e.g., four vs. no children, aOR = 1.53; $95 \% \mathrm{CI}=1.07,2.18)$. Women residing in a household where the income was $\$ 1.00 \mathrm{USD} /$ day or higher had $41 \%$ higher odds of VCT awareness ( $\mathrm{aOR}=1.41,95 \% \mathrm{CI}=1.06,1.86)$. We did not detect an association between women residing in households where electricity was available versus not, but mobile phone ownership was associated with increased awareness of VCT $(\mathrm{aOR}=1.37 ; 95 \% \mathrm{CI}=1.03,1.84)$. Additionally, a non-linear relationship of social exclusion stigma was noted with VCT awareness, such that persons having very low levels of social exclusion stigma or with moderate to high levels had the lowest odds of VCT awareness. Having a higher numeracy score was also significantly associated with having heightened awareness of VCT $(\mathrm{aOR}=1.05$, CI 1.03, 1.08); specifically, for every 
1-point increase in numeracy score, one's odds of VCT awareness were increased by $5 \%$. As well-being scores increased on the QoL scale, women were increasingly more aware of VCT, $(\mathrm{aOR}=1.06$; $95 \%$ CI $1.00,1.13)$; specifically, for each 1-point increase in QoL score, the odds of VCT awareness increased by $6 \%$. Little association with VCT awareness was noted for the Negative Labeling and Devaluation Stigma Scale $(\mathrm{p}=0.7)$.

\section{Aware but never tested in VCT vs. aware and ever tested in VCT}

In the second model among women who were aware of $V C T(\mathrm{n}=1,162), 58 \%$ (unweighted $\mathrm{n}=673)$ remained untested in a VCT setting, while $42 \%$ (unweighted $n=489$ ) had tested previously. Among these VCT-aware women, women with 2 children were most likely to have tested $(\mathrm{aOR}=1.63 ; 95 \% \mathrm{CI}=1.12-2.36$ vs. 0 children). Having children under the age of 5 was the only covariate significantly associated with both being aware of VCT as well as being aware and undergoing VCT. Among VCT-aware women, those with high stigma scores ( $\geq 80$ points on the Negative Labeling and Devaluation Stigma Scale) were 59\% less likely to be tested $(\mathrm{aOR}=0.41 ; 95 \% \mathrm{CI}=0.23,0.71$ [20 pts ref]; $\mathrm{p}<0.001)$ compared to those with lower stigma scores.

\section{Discussion}

In this systematic, province-wide assessment of female respondents across Zambézia province, less than one-third of women were aware that VCT was locally available. Expanding this service awareness is a critical first step in the early identification of new HIV infections. Awareness of VCT was higher among those who were younger, resided in an urban area, and had greater socio-economic advantages (highly educated, primarily Portuguese speaking, relatively wealthy, and/or a mobile phone user). Awareness was also higher among participants residing in closer proximity to a health facility, reporting a higher quality of life, and having less stigmatizing attitudes. Being multiparous and caring for greater than or equal to 2 living children was highly associated with VCT awareness and uptake, suggesting that testing awareness might be increasing during and after pregnancy, presumably due to prevention of mother to child HIV transmission (PMTCT) services.

A successful strategy for VCT requires that testing is available, the public is aware of such services, and that a person is able to overcome potential barriers and attend the facility offering VCT [57]. While several prior studies investigated barriers to various forms of VCT access and factors related to the acceptance or refusal of these services in predominantly rural areas, our study looks further upstream and describes factors related to the actual awareness of the availability of these services (a necessary prerequisite to uptake) [2,9,58-62]. Given
Mozambique's historically low national rate of VCT uptake (14\% for women in 2009) [16,63], compounded by Zambézia's very high rates of illiteracy $(50 \%$ among Portuguese speakers and 94\% among non-Portuguese speakers) and their low numeracy levels (mean score corresponding to US kindergarten-level skills) [29], these findings suggest increased efforts are needed to expand basic awareness and knowledge related to VCT if service uptake is to be increased. Similar to our findings, a Tanzanian study found that only $45 \%$ of women in a rural cohort were aware of VCT services, a finding that was negatively associated with VCT uptake [4]. While Zambézia Province could benefit from enhanced efforts to expand knowledge and availability of VCT, outreach must be tailored to a local language that women understand.

Most women in Zambézia reside in remote, rural communities with pronounced socio-economic disadvantages. When women become pregnant in Zambézia, they are offered opt-out HIV testing during antenatal care (i.e. provider initiated counseling and testing). As women have more children their awareness and utilization of VCT seemed to have increased, independent of a woman's age. This is due perhaps to their pregnancy-related exposure to the health care system. Several investigators reported a positive association of increased exposure to the health care system and VCT uptake [63-65]. As of 2010, the majority of Zambézian women did routinely access health facilities antenatally; however, nearly $40 \%$ did not go to the facility during their last pregnancy missing opportunities to receive HIV testing in a PMTCT setting [18]. In addition to scaling up antenatal services, we recommend integrating VCT services concurrently with postnatal care and childcare visits.

A very strong predictor of a woman being unaware of VCT was her stigmatizing view of PLWHA, supporting their social exclusion. Negative labeling and devaluation were predictors for being less likely to test. A refusal to test that is associated with higher stigma has been seen in other studies [64,66-69]. Campaigns designed to address and reduce stigma, if successful, may facilitate VCT uptake.

Strengths of our study include the representative reach of our survey, the access to remote rural areas typically neglected in research, the use of local languages to gather data, the comfort women had responding from the privacy of their homes, and the size of our sample in a remote, understudied setting. Limitations to our study include those familiar to a cross-sectional survey, including respondent reporting bias and the potential for miscommunication and misclassification of results due to variety of local languages and dialects in the province (though we interviewed in any of six languages). Household ownership of a mobile phone was ascertained via the respondent's spouse's possession of a mobile (not the respondent 
herself). We could not cross-reference VCT uptake self-reports against medical records. In addition, the VCT program in Mozambique changed its name in 2006-2007 to be less specific for HIV and to include a broader context of health issues in order to reduce stigma associated with testing for HIV; the survey referred to the old name and not the new one, though our interviewers do not believe that this affected responses.

\section{Conclusions}

In summary, our survey of 3,708 female heads of household in rural Zambézia Province, Mozambique, found that a majority of women were unaware of VCT availability and most women who were aware of these services had not used them. Increased efforts are required to expand knowledge and the availability of VCT among women in this rural context; and ideally campaigns should be tailored to a woman's specific sociolinguistic context. Rural community based testing and counseling via mobile brigades [59,70-75] and door-to-door campaigns [74,76-88] can be effective and could potentially impact Zambézia.

Another option may be incorporating such interventions into existing perinatal and post-natal healthcare visits where women are likely to attend for their child's care. Finally, Provider-initiated counseling and testing (PICT) strategies should be promulgated far more aggressively to enable HIV-infected women to be identified and subsequently started earlier on ART.

\section{Competing interest}

The authors declare that they have no competing interests.

\section{Authors' contributions}

HNP conceived and designed the study, wrote, and edited the manuscript. MB performed the data analysis, wrote, and edited the manuscript. JRK conceived and designed the study, wrote, and edited the manuscript. $\mathrm{NH}$ performed the data analysis and edited the manuscript. LMEV implemented the parent study, collected parent study data, wrote, and edited the manuscript. AEV implemented the parent study, collected parent study data, conceived and designed the study, and edited the manuscript. AM edited the manuscript and is a study expert on HIV Stigma. EN edited the manuscript and is a study expert in Mozambique. TM wrote and edited the manuscript. SHV wrote and edited the manuscript. CWW conceived and designed the study, wrote, and edited the manuscript. All authors have read approved the final manuscript.

\section{Acknowledgements}

We thank the Ogumaniha-SCIP team members and survey respondents.

\section{Funding}

This manuscript was supported by the United States Agency for International Development (USAID)-Mozambique (Award No. 656-A-00-09-00141-00) through a sub-grant from World Vision, Inc. The funders had no role in study design, data collection and analysis, decision to publish, or preparation of the manuscript. The contents are the responsibility of the authors and do not necessarily reflect the views of USAID, the United States Government, or World Vision, Inc.

\section{Author details}

'Department of Medicine, Division of Infectious Diseases, Vanderbilt University School of Medicine, 1611 21st Avenue South, A-2200, Medical Center North, Nashville, TN, USA. ${ }^{2}$ Department of Biostatistics, Nashville, TN, USA. ${ }^{3}$ Department of Pediatrics, Nashville, TN, USA. ${ }^{4}$ Department of Preventive Medicine, Nashville, TN, USA. ${ }^{5}$ Vanderbilt University, Vanderbilt Institute for Global Health (VIGH), Nashville, TN, USA. ${ }^{6}$ Friends in Global Health (FGH), Maputo, Mozambique. ${ }^{7}$ Save the Children, Washington, D.C., USA.

Received: 27 June 2014 Accepted: 9 January 2015

Published online: 12 February 2015

\section{References}

1. Helleringer S, Kohler HP, Frimpong JA, Mkandawire J. Increasing uptake of HIV testing and counseling among the poorest in sub-Saharan countries through home-based service provision. J Acquir Immune Defic Syndr. 2009:51(2):185-93.

2. Morin SF, Khumalo-Sakutukwa G, Charlebois ED, Routh J, Fritz K, Lane T, et al. Removing barriers to knowing HIV status: same-day mobile HIV testing in Zimbabwe. J Acquir Immune Defic Syndr. 2006;41(2):218-24.

3. Were WA, Mermin JH, Wamai N, Awor AC, Bechange S, Moss S, et al. Undiagnosed HIV infection and couple HIV discordance among household members of HIV-infected people receiving antiretroviral therapy in Uganda. J Acquir Immune Defic Syndr. 2006;43(1):91-5.

4. Wringe A, Isingo R, Urassa M, Maiseli G, Manyalla R, Changalucha J, et al. Uptake of HIV voluntary counselling and testing services in rural Tanzania: implications for effective HIV prevention and equitable access to treatment. Trop Med Int Health. 2008;13(3):319-27.

5. WHO, UNAIDS, UNICEF. Scaling up priority HIV/AIDS interventions in the health sector, Progress report 2010. September, 2010. [http://www.who.int/ hiv/pub/2010progressreport/report/en/index.html]

6. Mossdorf E, Stoeckle M, Vincenz A, Mwaigomole EG, Chiweka E, Kibatala P, et al. Impact of a national HIV voluntary counselling and testing $(V C T)$ campaign on VCT in a rural hospital in Tanzania. Trop Med Int Health. 2010;15(5):567-73.

7. Karau PB, Winnie MS, Geoffrey M, Mwenda M. Responsiveness to HIV education and $V C T$ services among Kenyan rural women: a community-based survey. Afr J Reprod Health. 2010;14(3):165-9.

8. Isingo R, Wringe A, Todd J, Urassa M, Mbata D, Maiseli G, et al. Trends in the uptake of voluntary counselling and testing for HIV in rural Tanzania in the context of the scale up of antiretroviral therapy. Trop Med Int Health. 2012;17(8):e15-25.

9. Sherr L, Lopman B, Kakowa M, Dube S, Chawira G, Nyamukapa C, et al. Voluntary counselling and testing: uptake, impact on sexual behaviour, and HIV incidence in a rural Zimbabwean cohort. AIDS. 2007;21 (7):851-60.

10. Moon TD, Burlison JR, Blevins M, Shepherd BE, Baptista A, Sidat M, et al. Enrolment and programmatic trends and predictors of antiretroviral therapy initiation from president's emergency plan for AIDS Relief (PEPFAR)-supported public HIV care and treatment sites in rural Mozambique. Int J STD AIDS. 2011;22(11):621-7.

11. Castelli F, Pietra V, Diallo I, Schumacher RF, Simpore J. Antiretroviral (ARV) Therapy in Resource Poor Countries: What do we Need in Real Life? Open AIDS J. 2010;4:28-32.

12. Makwiza I, Nyirenda L, Bongololo G, Banda T, Chimzizi R, Theobald S. Who has access to counseling and testing and anti-retroviral therapy in Malawi - an equity analysis. Int J Equity Health. 2009;8:13.

13. Bwambale FM, Ssali SN, Byaruhanga S, Kalyango JN, Karamagi CA. Voluntary HIV counselling and testing among men in rural western Uganda: implications for HIV prevention. BMC Public Health. 2008;8:263.

14. Tabana H, Doherty T, Swanevelder S, Lombard C, Jackson D, Zembe W, et al. Knowledge of HIV status prior to a community HIV counseling and testing intervention in a rural district of south Africa: results of a community based survey. BMC Infect Dis. 2012;12:73.

15. Instituto Nacional de Saúde (INS), Instituto Nacional de Estatística (INE), e ICF Macro. Inquérito Nacional de Prevalência, Riscos Comportamentais e Informação sobre o HIV e SIDA em Moçambique 2009. Calverton, Maryland, EUA: INS, INE e ICF Macro. 2010. [http://www.misau.gov.mz/index.php/ inqueritos-de-saude]

16. UNAIDS. Global Report. UNAIDS Report On The Global AIDS Epidemic. 2010. [http://www.unaids.org/globalreport/documents/20101123_GlobalReport_ full_en.pdf] 
17. UNAIDS. Universal Declaration of Commitment on HIV and AIDS, Mozambique Progress Report 2006-2007. United Nations General Assembly Special Session on HIV/AIDS. January, 2008. [http://data.unaids.org/pub/ Report/2008/mozambique_2008_country_progress_report_en.pdf]

18. Vergara AE, Blevins M, Vaz LM, Manders EJ, Gonzalez LC, Arregui C, Green A. Baseline Survey Report, December 12, 2011, SCIP - Ogumaniha: Improving health and livelihoods of children, women and families in the Province of Zambézia, Republic of Mozambique Phase I and II: Zambézia-wide. 2011. [http://globalhealth.vanderbilt.edu/programs/scip/]

19. Audet $C M$, Burlison J, Moon TD, Sidat M, Vergara AE, Vermund SH. Sociocultural and epidemiological aspects of HIV/AIDS in Mozambique BMC Int Health Hum Rights. 2010;10:15.

20. UNAIDS. Mozambique Progress Report 2008-2009. United Nations General Assembly Special Session on HIV/AIDS. March, 2010. [http://data.unaids.org/ pub/Report/2008/mozambique_2008_country_progress_report_en.pdf]

21. Donnell D, Baeten JM, Kiarie J, Thomas KK, Stevens W, Cohen CR, et al. Heterosexual HIV-1 transmission after initiation of antiretroviral therapy: a prospective cohort analysis. Lancet. 2010;375(9731):2092-8.

22. Del Romero J, Castilla J, Hernando V, Rodriguez C, Garcia S. Combined antiretroviral treatment and heterosexual transmission of HIV-1: cross sectional and prospective cohort study. BMJ. 2010;340:c2205.

23. Reynolds SJ, Makumbi F, Nakigozi G, Kagaayi J, Gray RH, Wawer M, et al. HIV-1 transmission among HIV-1 discordant couples before and after the introduction of antiretroviral therapy. AIDS. 2011;25(4):473-7.

24. Cohen MS, Chen YQ, McCauley M, Gamble T, Hosseinipour MC, Kumarasamy N, et al. Prevention of HIV-1 infection with early antiretroviral therapy. N Engl J Med. 2011;365(6):493-505.

25. Lahuerta M, Lima J, Elul B, Okamura M, Alvim MF, Nuwagaba-Biribonwoha $\mathrm{H}$, et al. Patients enrolled in HIV care in Mozambique: baseline characteristics and follow-up outcomes. J Acquir Immune Defic Syndr. 2011;58(3):e75-86.

26. Mozambqiue Ministry of Health. Dados TARV Nacionais ate Dezembro 2011. [http://www.misau.gov.mz/index.php/hiv-sida/cat_view/82-hivsida/89informacao-estrategica-relatorios/90-relatorios-tarv]

27. Portal da Governo da Provincia Zambézia. Zambézia. 2008. [http://www. zambezia.gov.mz/zambezia]

28. Instituto Nacional de Estatística. Estatísticas Do Distrito. Cidade De Quelimane - 2008. 2010. [http://www.ine.gov.mz/estatisticas/estatisticasterritorias-distritais/zambezia/2008/estatisticas-do-distrito-de-cidade-dequelimane.pdf/view]

29. Ciampa PJ, Vaz LM, Blevins M, Sidat M, Rothman RL, Vermund SH, et al. The association among literacy, numeracy, HIV knowledge and health-seeking behavior: a population-based survey of women in rural Mozambique. PLoS One. 2012;7(6):e39391.

30. Mozambique Ministry of Health. Multi-Sectoral Technical Group for the Fight Against HIV/AIDS in Mozambique: Report on the Revision of the Data for HIV Epidemiological Surveillance: Round 2007. 2008.

31. Roura M, Watson-Jones D, Kahawita TM, Ferguson L, Ross DA. Provider-initiated testing and counselling programmes in sub-Saharan Africa: a systematic review of their operational implementation. AIDS. 2013;27(4):617-26.

32. Sen A. Development as freedom. Oxford: Oxford University Press; 1999

33. DHS. Model questionnaire with commentary. In MEASURE DHS Basic Documentation Number 2 ORC Macro. Calverton, Maryland: DHS; July 2006.

34. Wilkinson GS. WRAT: Wide Range Achievement Test Administration Manual. Wilmington, DE: Wide Range, Inc; 1993.

35. Grant MJ. Children's school participation and HIV/AIDS in rural Malawi. The role of parental knowledge and perceptions. Demogr Res. 2008;19(45):1603-34.

36. Lockheed ME, Fuller B, Nyirongo R. Family effects on student's achievement in Thailand and Malawi. Sociol Educ. 1989:62(4):239-56.

37. Food and Agriculture Organization of the United Nations Nutrition and Consumer Protection Division. Guidelines for measuring household and individual dietary diversity. 2008.

38. Coates J, Swindale A, Bilinsky P. Household Food Insecurity Access Scale (HFIAS) for measurement of food access: indicator guide VERSION 3. Washington, DC: Food and Nutrition Technical Assistance Project; 2007.

39. Tirivayi N, Koethe JR, Groot W. Clinic-based food assistance is associated with increased medication adherence among HIV-infected adults on long-term antiretroviral therapy in Zambia. J AIDS Clin Res. 2012;3(7):171.

40. DHS. Demographic and health survey 5: Model household questionnaire (modified). 2010
41. Government of South Africa. Community Survey. 2007.

42. Pradhan MM, Ravallion MM. Measuring poverty using qualitative perceptions of consumption adequacy. Rev Econ Stat. 2000;82(3):462-71.

43. World Bank. Pesquisa de orcamentos familiares. 2007

44. UNICEF. Multiple indicator cluster surveys. 2010.

45. Wold BK. A sustainable household survey based poverty monitoring system. Norway Development Cooperation. 2004.

46. Oxford Poverty and Human Development Initiative. Missing dimensions of poverty data: a proposal for international comparable indicators. 2010.

47. Buiya A, Mahmood SS, Rana AK, Wahed T, Ahmed SM, Cowdhury AM. A multidimensional approach to measure poverty in rural Bangladesh. J health population Nutrition. 2007;25(2):134-45.

48. Pulerwitz J, Baker G. Measuring attitudes towards gender norms among young men in Brazil: Development and psychometric evaluation of the GEM scale. Men and Masculinities. 2007;10(3):322-38.

49. ChildInfo. Monitoring the situation of women and children. 2010. [http://www.childinfo.org/mics4_questionnaire.html]

50. Vaux A, Phillips J, Holly L. The social support appraisals (SS-A) scale: Studies of reliability and validity. Am J Community Psychol. 1986;14(2):195-218.

51. Population Council. Brazilian truck driver stigma study. 2003

52. World Health Organization. WHOQOL: Measuring quality of life. WHOQOL Group: WHO Programme on Mental Health, WHO/MSA/MNH/PSF/97.4.1. 1997.

53. World Health Organization. Introducing the WHOOOL instruments. Department of Mental Health and Substance Dependence. 1998.

54. World Health Organizaiton. WHOQOL-HIV instrument, in scoring and coding for the WHOQOL-HIV instruments. Mental Health: Evidence and Research Department of Mental Health and Substance Abuse. 2002.

55. Mukolo A, Blevins M, Victor B, Vaz LM, Sidat M, Vergara A. Correlates of social exclusion and negative labeling and devaluation of people living with HIV/AIDS in rural settings: evidence from a general household survey in Zambézia Province, Mozambique. PLoS One. 2013;8(10):e75744.

56. Harrell FE. Regression modeling strategies with applications to linear models, logistic regression, and survival analysis. New York, NY: Springer; 2001.

57. Matovu JK, Makumbi FE. Expanding access to voluntary HIV counselling and testing in sub-Saharan Africa: alternative approaches for improving uptake, 2001-2007. Trop Med Int Health. 2007;12(11):1315-22.

58. Kranzer K, McGrath N, Saul J, Crampin AC, Jahn A, Malema S, et al. Individual, household and community factors associated with HIV test refusal in rural Malawi. Trop Med Int Health. 2008:13(11):1341-50.

59. Ostermann J, Reddy EA, Shorter MM, Muiruri C, Mtalo A, Itemba DK, et al. Who tests, who doesn't, and why? Uptake of mobile HIV counseling and testing in the Kilimanjaro Region of Tanzania. PLoS One. 2011:6(1):e16488

60. deGraft-Johnson J, Paz-Soldan V, Kasote A, Tsui A. HIV voluntary counseling and testing service preferences in a rural Malawi population. AIDS Behav. 2005:9(4):475-84.

61. Silvestri DM, Modjarrad K, Blevins ML, Halale E, Vermund SH, McKinzie JP. A comparison of HIV detection rates using routine opt-out provider-initiated HIV testing and counseling versus a standard of care approach in a rural African setting. J Acquir Immune Defic Syndr. 2011;56(1):e9-32.

62. Matovu JK, Gray RH, Makumbi F, Wawer MJ, Serwadda D, Kigozi G, et al. Voluntary HIV counseling and testing acceptance, sexual risk behavior and HIV incidence in Rakai, Uganda. AIDS. 2005;19(5):503-11.

63. Mitchell S, Cockcroft A, Lamothe G, Andersson N. Equity in HIV testing: evidence from a cross-sectional study in ten Southern African countries. BMC Int Health Hum Rights. 2010;10:23.

64. Weiser SD, Heisler M, Leiter K, Percy-de Korte F, Tlou S, DeMonner S, et al. Routine HIV testing in Botswana: a population-based study on attitudes, practices, and human rights concerns. PLoS Med. 2006:3(7):e261.

65. MacPhail C, Pettifor A, Moyo W, Rees H. Factors associated with HIV testing among sexually active South African youth aged 15-24 years. AIDS Care 2009;21(4):456-67.

66. Obermeyer CM, Osborn M. The utilization of testing and counseling for HIV: a review of the social and behavioral evidence. Am J Public Health. 2007;97(10):1762-74.

67. Kalichman SC, Simbayi LC. HIV testing attitudes, AIDS stigma, and voluntary HIV counselling and testing in a black township in Cape Town, South Africa. Sex Transm Infect. 2003;79(6):442-7.

68. Sweat M, Morin S, Celentano D, Mulawa M, Singh B, Mbwambo J, et al Community-based intervention to increase HIV testing and case detection 
in people aged $16-32$ years in Tanzania, Zimbabwe, and Thailand (NIMH Project Accept, HPTN 043): a randomised study. Lancet Infect Dis. 2011;11(7):525-32.

69. Wolfe WR, Weiser SD, Bangsberg DR, Thior I, Makhema JM, Dickinson DB, et al. Effects of HIV-related stigma among an early sample of patients receiving antiretroviral therapy in Botswana. AIDS Care. 2006:18(8):931-3.

70. Chamie G, Kwarisiima D, Clark TD, Kabami J, Jain V, Geng E, et al. Leveraging rapid community-based HIV testing campaigns for non-communicable diseases in rural Uganda. PLoS One. 2012;7(8):e43400.

71. Chirawu P, Langhaug L, Mavhu W, Pascoe S, Dirawo J, Cowan F. Acceptability and challenges of implementing voluntary counselling and testing (VCT) in rural Zimbabwe: evidence from the Regai Dzive Shiri Project. AIDS Care. 2010;22(1):81-8.

72. Lugada E, Millar D, Haskew J, Grabowsky M, Garg N, Vestergaard M, et al. Rapid implementation of an integrated large-scale HIV counseling and testing, malaria, and diarrhea prevention campaign in rural Kenya. PLoS One. 2010;5(8):e12435.

73. van Rooyen H, McGrath N, Chirowodza A, Joseph P, Fiamma A, Gray G, et al Mobile VCT: reaching men and young people in urban and rural South African pilot studies (NIMH Project Accept, HPTN 043). AIDS Behav. 2013;17(9):2946-53.

74. Maheswaran H, Thulare H, Stanistreet D, Tanser F, Newell ML. Starting a home and mobile HIV testing service in a rural area of South Africa. J Acquir Immune Defic Syndr. 2012;59(3):e43-6.

75. Suthar AB, Ford N, Bachanas PJ, Wong VJ, Rajan JS, Saltzman AK, et al. Towards universal voluntary HIV testing and counselling: a systematic review and meta-analysis of community-based approaches. PLoS Med. 2013;10(8):e1001496.

76. Gonzalez R, Munguambe K, Aponte J, Bavo C, Nhalungo D, Macete E, et al. High HIV prevalence in a southern semi-rural area of Mozambique: a community-based survey. HIV Med. 2012;13(10):581-8.

77. Kimaiyo S, Were MC, Shen C, Ndege S, Braitstein P, Sidle J, et al. Home-based HIV counselling and testing in western Kenya. East Afr Med J. 2010;87(3):100-8.

78. Matovu JK, Kigozi G, Nalugoda F, Wabwire-Mangen F, Gray RH. The Rakai Project counselling programme experience. Trop Med Int Health. 2002;7(12):1064-7.

79. Medley A, Ackers M, Amolloh M, Owuor P, Muttai H, Audi B, et al. Early uptake of HIV clinical care after testing HIV-positive during home-based testing and counseling in western Kenya. AIDS Behav. 2013;17(1):224-34.

80. Molesworth AM, Ndhlovu R, Banda E, Saul J, Ngwira B, Glynn JR, et al. High accuracy of home-based community rapid HIV testing in rural Malawi. J Acquir Immune Defic Syndr. 2010;55(5):625-30.

81. Mutale W, Michelo C, Jurgensen M, Fylkesnes K. Home-based voluntary HIV counselling and testing found highly acceptable and to reduce inequalities. BMC Public Health. 2010;10:347.

82. Naik R, Tabana H, Doherty T, Zembe W, Jackson D. Client characteristics and acceptability of a home-based HIV counselling and testing intervention in rural South Africa. BMC Public Health. 2012;12:824.

83. Negin J, Wariero J, Mutuo P, Jan S, Pronyk P. Feasibility, acceptability and cost of home-based HIV testing in rural Kenya. Trop Med Int Health. 2009;14(8):849-55.

84. Tumwesigye E, Wana G, Kasasa S, Muganzi E, Nuwaha F. High uptake of home-based, district-wide, HIV counseling and testing in Uganda. AIDS Patient Care STDS. 2010;24(11):735-41.

85. Wawer MJ, Gray RH, Sewankambo NK, Serwadda D, Paxton L, Berkley S, et al. A randomized, community trial of intensive sexually transmitted disease control for AIDS prevention, Rakai. Uganda AIDS. 1998;12(10):1211-25.

86. Welz T, Hosegood V, Jaffar S, Batzing-Feigenbaum J, Herbst K, Newell ML. Continued very high prevalence of HIV infection in rural KwaZulu-Natal, South Africa: a population-based longitudinal study. AIDS. 2007:21(11):1467-72.

87. Were W, Mermin J, Bunnell R, Ekwaru JP, Kaharuza F. Home-based model for HIV voluntary counselling and testing. Lancet. 2003;361(9368):1569.

88. van Rooyen H, Barnabas RV, Baeten JM, Phakathi Z, Joseph P, Krows M, et al. High HIV testing uptake and linkage to care in a novel program of home-based HIV counseling and testing with facilitated referral in KwaZulu-Natal, South Africa. J Acquir Immune Defic Syndr. 2013;64(1):e1-8.

\section{Submit your next manuscript to BioMed Central and take full advantage of:}

- Convenient online submission

- Thorough peer review

- No space constraints or color figure charges

- Immediate publication on acceptance

- Inclusion in PubMed, CAS, Scopus and Google Scholar

- Research which is freely available for redistribution 